\title{
The impact of quality of care on contraceptive use: Evidence from longitudinal data from rural Bangladesh
}

Michael A. Koenig

Follow this and additional works at: https://knowledgecommons.popcouncil.org/departments_sbsr-rh

Part of the Demography, Population, and Ecology Commons, Health Services Research Commons, and the International Public Health Commons How does access to this work benefit you? Let us know!

\section{Recommended Citation}

Koenig, Michael A. 2003. "The impact of quality of care on contraceptive use: Evidence from longitudinal data from rural Bangladesh," FRONTIERS Final Report. Washington, DC: Population Council. 


\title{
The Impact of Quality of Care on Contraceptive Use: Evidence from Longitudinal Data from Rural Bangladesh
}

\author{
Michael A. Koenig
}

September 2003
Department of Population and Family Health Sciences
Bloomberg School of Public Health
The Johns Hopkins University
615 N. Wolfe Street
Baltimore, MD 21205
Co-Investigators:
Saifuddin Ahmed, Population and Family Health Sciences
Mian Bazle Hossain, Morgan State University

This study was funded by the U.S. AGENCY FOR INTERNATIONAL DEVELOPMENT (USAID) under the terms of Cooperative Agreement number HRN-A-00-98-00012-00 and Population Council Subagreement Number AI01.10A. The opinions expressed herein are those of the authors and do not necessarily reflect the view of USAID. 


\section{Background}

The Department of Population and Family Health Sciences at the Johns Hopkins Bloomberg School of Public Health conducted research on the impact of service quality for contraceptive utilization with the support of the Population Council's Frontiers in Reproductive Health Program. The project analyzed secondary data from a longitudinal surveillance area maintained by the International Center for Diarrhoeal Disease Research, Bangladesh in two rural areas of Bangladesh during the 198992 period.

Over the last decade, quality of care has emerged as a central organizing principle for family planning services in developing countries. This emphasis has been predicated on the assumption that poor quality of care has been a primary factor behind the low utilization of family planning services in many settings. Improvements in quality are expected to result in increases in contraceptive use and use-effectiveness, and thus, the ability of couples to achieve their desired reproductive goals. Despite a decade of interest in this issue, however, convincing empirical evidence on the impact of quality of care on contraceptive use and fertility behavior continues to be limited.

This project was intended to address this gap through analysis of a unique longitudinal data set from rural Bangladesh. Using prospective data from approximately 7,000 reproductive-aged Bangladeshi women, the objective of this study was to evaluate the relative impact of service quality and client characteristics on contraceptive adoption and method continuation. The study employed new, more methodologically rigorous analytical approaches - specifically, multi-level analysis - and measures of fieldworker and clinic service access and quality, which are largely free from the biases of endogeneity (i.e. the inter-correlation of key variables) and unobserved heterogeneity which characterize many existing analyses of this issue. The results provide new and persuasive empirical evidence on the importance of service quality for contraceptive behavior.

\section{Analytical approach}

Potential endogeneity is a central methodological issue confronting analyses of the impact of programmatic variables on contraceptive behavior. One source of endogeneity concerns program placement - whereby services are more likely to be situated in areas of high demand for family planning services. While this may apply most readily to the placement of clinical facilities (Bertrand, 
et al. 1996), it may also arise from outreach workers who target their visits to women/couples most inclined to adopt contraception. Other, equally serious potential sources of endogeneity relate to individuals' perceptions of service providers, and overall service programs being affected by clients' inclinations to adopt contraception. Stated simply: Does higher perceived quality of care result in improved contraceptive behavior? Or alternatively, are clients who are more motivated to adopt and effectively use contraception more likely to perceive providers favorably, or to be visited by the service program? In both cases, there is the possibility of reverse causality: motivation to adopt contraception leads to either increased access/visitation by program staff, or to more positive views of the service providers and programs, inflating the association between service variables and contraceptive practice.

Several approaches have been adopted to address the problem of program endogeneity. One approach uses evidence from actual experimental or (more commonly) quasi-experimental field studies, which, while the preferred approach, has generally been constrained by only limited observed impact on service quality (Sanogo, et al. 2003; Patel, et al. 1999). A second approach has been to use individual-level program data but to attempt to statistically adjust for endogeneity through the use of two-stage least squares techniques. Uncertainties persist regarding the extent to which bias is removed from these estimates (Pariani, et al., 1991; Koenig, et al. 1997). A more common approach in recent years has been to combine population-based data on contraceptive behavior (most commonly from DHS surveys) with independent, external data capturing service availability or quality. While this approach resolves many of the previously described methodological problems concerning endogeneity, it is also characterized by potentially serious measurement error issues.

One variation of this approach uses data on service quality from key informants other than survey respondents (see, for example, Mroz, 1999). This approach, however, suffers from a number of limitations including: 1) questions about the accuracy and completeness of knowledge of these key informants, especially given that many may not be actual contraceptive users; 2) indications that informants may often be chosen based on availability, rather than personal expertise, and from large catchments areas with respect to service delivery points (e.g. in a radius of 30 kilometers); and 3) continued uncertainty about whether the service facilities measured in the study are those actually used by clients. 
A second variation of this approach combines population-based data on contraceptive practice with program variables measured through DHS facility assessment surveys (Mensch, et al. 1996; Magnani, et al. 1999; Steele, et al. 1999). This approach is also not without significant limitations. First, these assessments more appropriately measure facility readiness to provide services, rather than actual service delivery, especially in relation to the multi-dimensional component of service quality. This approach has not proven particularly useful in assessing the interpersonal dimensions of quality of care, which may be critical in influencing clients' contraceptive behavior (Vera, 1993). Moreover, given that multiple service points are frequently accessible to individual respondents, questions persist concerning whether the service delivery points measured are actually those used by respondents. ${ }^{1} \mathrm{~A}$ third important limitation of this approach is its focus on clinical services and poorer suitability for community-based outreach programs, which in many settings represent an equally or more important source of family planning services.

In the present study, researchers adopted an alternative approach that addresses many of the major measurement issues outlined above. Measures of service quality are based on responses from survey respondents themselves, and focus heavily on the interpersonal aspects of client-provider interaction and service quality. The approach is based on econometric arguments often employed in program evaluation of non-experimental observational studies. Specifically, aggregated responses from all interviewed respondents associated with a specific worker or clinic area were used to create 'mean' quality scores at both the worker and clinic levels. ${ }^{2}$ In doing so, researchers were able to capture service quality as expressed by respondents themselves, largely free of the associated problems of response endogeneity.

\section{Description of Program Variables}

Each of the four key program variables measuring service access and quality is described in greater detail below.

Fieldworker-level quality of care index: Based on responses to a 1989 special survey, seven variables measuring service quality were calculated at the level of specific female fieldworkers in each

\footnotetext{
${ }^{1}$ One approach to this has been to take the average of all SDP's within a given catchment area surrounding a respondent. However, if respondents are willing to travel further for higher quality services, then this approach introduces significant measurement error into such analysis.

${ }^{2}$ We have used both arithmetic means as well as the mean minus the index case (commonly described as the jackknife mean), and compared the sensitivity of results.
} 


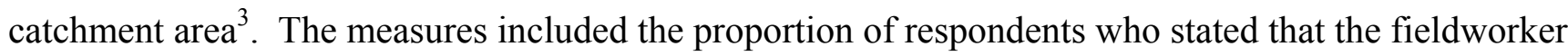
was usually or always responsive to her questions, appreciative of her need for privacy, someone who she could depend on to help with problems, sympathetic to her needs, and provides enough information. They also included the proportion of respondents who indicated that the fieldworker spent 10 or more minutes with them during their most recent visit, and those who reported being offered a choice of contraceptive methods by the fieldworker. A total of 66 female fieldworkers were assigned within the surveillance area. Factor analysis was then employed to create a quality of care factor score at the fieldworker level, and all respondents within a fieldworker's area were assigned the same factor score. 4

Fieldworker-level outreach: Using the same aggregation approach, the proportion of respondents within a catchment area who were visited one or more times during the previous six months was calculated and assigned to all respondents within that area.

Clinic-level quality of care: This variable was defined as the proportion of respondents within a given clinic catchment area who reported that they believe they usually or always receive good quality of care from the union-level clinic in their area. ${ }^{5}$ These measures were then aggregated to the clinic catchment level (corresponding to an administrative area in rural Bangladesh), and all individuals within the same catchment area were assigned this mean value. A total of 11 union-level clinic catchment areas were contained within the surveillance sites.

Clinic-level access: The distance (in kilometers) from a respondent's household to the union-level clinic was measured individually for each household in the study area.

Additional client demographic and socio-economic characteristics included as control variables include the woman's age, educational attainment, desire for additional children, religion, household area $(\log )$, whether the household possessed electricity, and woman's status (measured through an index).

\footnotetext{
${ }^{3}$ All fieldworkers in rural Bangladesh are assigned individual, non-overlapping field catchment areas.

${ }^{4}$ This approach had the additional advantage of allowing us to assign aggregated program values to the significant minority of respondents $(\sim 20 \%)$ who reported never having been visited by a fieldworker, since variables were constructed on a catchment area, rather than individual-level, basis.

${ }^{5}$ Public image (Bertrand,1996)
} 


\section{Analysis Results}

\section{Contraceptive Adoption}

The starting population for analysis of contraceptive adoption consisted of the 4,656 reproductiveaged women who were not using a modern contraceptive method at the time of the 1989 baseline survey. These women were followed until they adopted a modern method (e.g. sterilization, IUD, oral pills, condoms, injectables), out-migrated from the surveillance area, lost eligibility due to age or change in marital status, or until the end of the observation period 36 months after the baseline survey. Proportional hazards analysis was employed to counteract the problem of right censoring in the data. The model of contraceptive adoption is shown in Table 1.

The relationships between many of the non-programmatic variables and contraceptive adoption were largely as expected, with higher women's education, the desire for no additional children, higher socio-economic status (household area), and the household having electricity all associated with a significantly higher likelihood of subsequent adoption. Three of the four programmatic variables also emerged as significant predictors of subsequent contraceptive adoption. First, distance from the client's residence to the clinic was significantly inversely related to adoption. Clients who reside farther away from the clinic were significantly less likely to adopt contraception. Second, the aggregate measure of clinic quality of care was positively related to adoption - respondents who reside in catchment areas of clinics categorized as having high quality of care were significantly more likely $(\mathrm{HR}=1.56)$ to subsequently adopt a method. Third, the aggregate measure of fieldworker quality of care was systematically related to the likelihood of subsequent adoption. As shown in Figure 1, respondents served by fieldworkers categorized as providing moderate levels of quality of care were 44 percent more likely to adopt a method, while respondents served by fieldworkers providing high or very high quality of care were more than 60 percent more likely to subsequently adopt a method $(\mathrm{HR}=1.64$ and $1.62)$, relative to the poor quality reference group.

\section{Contraceptive Continuation}

The study population sample for analysis of contraceptive continuation was the subset of women who either adopted non-permanent methods (e.g. oral pills, injectables, IUDs, condoms) at the time of the 1989 KAP survey, or who adopted a temporary method during the subsequent three-year period. In total 3,611 temporary method users were included in the starting study population. The determinants of both firstmethod continuation (only the first method adopted) and all-method continuation (all methods used 
continuously, which allows for method switching) were explored. The outcome variable was defined as a dichotomous variable (i.e. continued contraceptive method use $=0$; discontinued method use $=1$ ). Again, respondents were followed until discontinuation of the method(s), out-migration from the surveillance area, loss of eligibility due to age or change in marital status, or the end of the observation period at 36 months after the baseline survey. Given the problem of right censoring in the data, researchers again employed proportional hazards analysis.

\section{First-Method Continuation}

Table 2 presents results for first-method continuation. In contrast to findings on contraceptive adoption, fieldworker quality of care was no longer significantly related to the likelihood of first-method continuation. Fieldworker outreach visitation was, however, strongly related. Among respondents served by fieldworkers, clients receiving higher rates of visitation were significantly more likely to continue use of their method. Distance to the clinic was, in contrast to the findings for method adoption, also now not significantly related to first-method continuation. Perceived quality of care at the clinic was weakly related to first-method continuation. Method users who reside in areas characterized by high quality of care were 22 percent less likely to continue their first method, perhaps because higher quality clinics offer a broader range of methods to choose from, and providers may encourage users to switch methods if they are dissatisfied with their first choice.

\section{All-Method Continuation}

Table 3 presents findings for the determinants of all-method contraceptive continuation. Findings show that neither clinic access nor quality of care remain statistically significant determinants of continuation. Higher fieldworker outreach visitation was associated with higher rates of all-method continuation. In contrast to first-method continuation, fieldworker quality of care was systematically related to all-method continuation; contraceptive users served by fieldworkers characterized by high or very high levels of service quality were 28 and 34 percent more likely, respectively, to continue any method use.

Does the importance of service quality for contraceptive behavior depend on client socio-economic status?

A question largely unexplored in previous studies on the impact of quality of care is whether the importance of quality of care varies according to individual client characteristics. This study examined 
two key indicators of socio-economic status - maternal education and household area. Figure 3 summarizes the findings on the effects of fieldworker quality of care, net of all other covariates shown in previous models. The analysis demonstrates that fieldworker quality of care is a significant and important determinant of subsequent contraceptive adoption for both uneducated women and women with some education, indicating that service quality is an important determinant for contraceptive adoption across socio-economic groups.

For all-method continuation, in contrast, the effects of quality vary according to educational level. Among uneducated women, fieldworker quality remains a significant determinant, with lower discontinuation rates among women served by higher quality fieldworkers. Among women with some education, in contrast, the effects of fieldworker quality of care were no longer significant. Similar results were evident when the sample was stratified by lower and higher socio-economic status as measured by household area. The results suggest that the quality of care provided by outreach workers represents an important factor in the decision to adopt contraception among all rural women in the study. Once adopted, continued use of a temporary method among women of lower socio-economic status remains significantly influenced by the quality of fieldworker care. Among more socioeconomically advantaged women, in contrast, fieldworker service quality no longer represents a key factor in the decision to continue/discontinue, with contextual and non-programmatic factors playing more important roles. These findings, taken as a whole, underscore the central importance of service quality in influencing poorer and uneducated women's contraceptive decisions and behaviors.

\section{Conclusions}

The findings from this project add important new and methodologically rigorous evidence to the emerging literature on the implications of service quality on contraceptive behavior. The results reaffirm the importance of female fieldworker outreach — both in terms of quality and the number of visits — on contraceptive use dynamics in rural Bangladesh. The findings are also broadly consistent with those from an earlier study of this issue (Koenig, et al. 1997), and provide compelling evidence that improvements in quality of care are likely to result in more effective contraceptive practice, as reflected in both greater acceptance and continued use.

In particular, the results reaffirm the importance of fieldworker quality for both contraceptive adoption and all-method continuation. Higher fieldworker quality of care is associated with about a 60 percent greater likelihood of subsequent adoption of a modern method, and roughly a one-third 
reduction in the likelihood of contraceptive method discontinuation. As in the earlier study, fieldworker quality of care was significantly related to higher all-method, but not first-method, continuation, reinforcing earlier conclusions that fieldworkers who provide better quality of care may better enable women to switch contraceptive methods if use of a particular method proves unsuitable for a client. Perceived clinic quality of care and greater access were also associated with significantly greater likelihoods of subsequent method adoption.

An important new finding from this study concerns the extent to which the effects of fieldworker quality of care on contraceptive practice may be conditional on the socio-economic characteristics of clients. The findings indicate that, with respect to contraceptive adoption, fieldworker quality of care remains an important determinant across all socio-economic strata. For all-method continuation, in contrast, fieldworker quality of care is a highly significant determinant for uneducated women and women in the lowest socio-economic strata (as measured by household area). Among more educated or socio-economically advantaged women, in contrast, service quality is not a significant factor affecting continuation.

In addition to these substantive findings, the study makes important methodological contributions in assessing the impact of programmatic variables - especially quality of care — on contraceptive use dynamics. The aggregated approach adopted has distinct advantages over conventional approaches that link population-based outcomes with service facility data because it captures the key interpersonal dimensions of provider-client interactions more effectively and more accurately measures the appropriate service delivery points/providers with whom clients actually interacted. This approach has wide future applications for further studies of the impact of program variables on contraceptive behaviors and for other reproductive health behaviors as well. 
Table 1. The effects of programmatic and non-programmatic variables on contraceptive adoption, rural Bangladesh, 1989-93.

Variable Hazard ratio S.E. p value

\section{Programmatic variables}

Fieldworker quality of care

Low (RC)

1.00

Moderate

$\begin{array}{lll}1.44 & 0.74 & 0.003\end{array}$

High

Very high

$\begin{array}{lll}1.64 & 0.27 & 0.000\end{array}$

$\begin{array}{lll}1.62 & 0.26 & 0.002\end{array}$

Fieldworker visitation $<6$ months

$\begin{array}{lll}0.84 & 0.15 & 0.332\end{array}$

Clinic quality of care

Low (RC)

1.00

Moderate

$\begin{array}{lll}1.21 & 0.14 & 0.090\end{array}$

High

$\begin{array}{lll}1.56 & 0.15 & 0.000\end{array}$

Distance to clinic

$\begin{array}{lll}0.92 & 0.03 & 0.005\end{array}$

Non-programmatic

\section{Women's age}

$<25$ years $(\mathrm{RC})$

1.00

25-34 years

$\begin{array}{lll}1.10 & 0.08 & 0.176\end{array}$

$35+$ years

$\begin{array}{lll}0.60 & 0.05 & 0.000\end{array}$

Women's education

None (RC)

1.00

1-5 years

$\begin{array}{lll}1.20 & 0.07 & 0.002\end{array}$

$6+$ years

$\begin{array}{lll}1.27 & 0.13 & 0.017\end{array}$

Desire for additional children

$1+$ more $(R C)$

1.00

No more

1.17

$0.09 \quad 0.042$

Up to God

$\begin{array}{lll}0.86 & 0.04 & 0.003\end{array}$

\section{Religion}

Muslim (RC)

1.00

Non-Muslim

$\begin{array}{lll}0.84 & 0.08 & 0.057\end{array}$

Household area (log)

$\begin{array}{lll}0.86 & 0.03 & 0.000\end{array}$

Electricity

No (RC)

1.00

Yes

$\begin{array}{lll}1.23 & 0.09 & 0.006\end{array}$

Women's status

$\begin{array}{lll}1.04 & 0.06 & 0.484\end{array}$

Wald $\mathrm{X}^{2}$

404.56

Probability

0.00

(N)

$-4610.00$

The Impact of Quality of Care on Contraceptive Use 
Table 2. The effects of programmatic and non-programmatic variables on first method contraceptive continuation, rural Bangladesh, 1989-93

\begin{tabular}{|c|c|c|c|}
\hline Variable & Hazard ratio & S.E. & $p$ value \\
\hline \multicolumn{4}{|l|}{ Programmatic variables } \\
\hline \multicolumn{4}{|l|}{ Fieldworker quality of care } \\
\hline Low (RC) & 1.00 & & \\
\hline Moderate & 0.99 & 0.11 & 0.940 \\
\hline High & 1.02 & 0.11 & 0.878 \\
\hline Very high & 0.94 & 0.11 & 0.613 \\
\hline Fieldworker visitation $<6$ months & 0.61 & 0.08 & 0.000 \\
\hline \multicolumn{4}{|l|}{ Clinic quality of care } \\
\hline Low $(\mathrm{RC})$ & 1.00 & & \\
\hline Moderate & 0.92 & 0.09 & 0.364 \\
\hline High & 1.22 & 0.12 & 0.039 \\
\hline Distance to clinic & 1.02 & 0.03 & 0.444 \\
\hline \multicolumn{4}{|l|}{ Non-programmatic } \\
\hline \multicolumn{4}{|l|}{ Women's age } \\
\hline$<25$ years $(\mathrm{RC})$ & 1.00 & & \\
\hline $25-34$ years & 0.78 & 0.05 & 0.000 \\
\hline $35+$ years & 0.64 & 0.05 & 0.000 \\
\hline \multicolumn{4}{|l|}{ Women's education } \\
\hline None (RC) & 1.00 & & \\
\hline $1-5$ years & 0.90 & 0.05 & 0.084 \\
\hline $6+$ years & 0.91 & 0.08 & 0.308 \\
\hline \multicolumn{4}{|l|}{ Desire for additional children } \\
\hline $1+$ more $(\mathrm{RC})$ & 1.00 & & \\
\hline No more & 0.74 & 0.04 & 0.000 \\
\hline Up to God & 0.92 & 0.06 & 0.207 \\
\hline \multicolumn{4}{|l|}{ Religion } \\
\hline Muslim (RC) & 1.00 & & \\
\hline Non-Muslim & 0.87 & 0.06 & 0.042 \\
\hline Household area (log) & 0.92 & 0.03 & 0.014 \\
\hline \multicolumn{4}{|l|}{ Electricity } \\
\hline No (RC) & 1.00 & & \\
\hline Yes & 0.99 & 0.07 & 0.843 \\
\hline Women's status & 1.02 & 0.05 & 0.674 \\
\hline \multicolumn{4}{|l|}{ Contraceptive Method } \\
\hline Oral pills & 1.97 & 0.19 & 0.000 \\
\hline Injectables & 1.66 & 0.18 & 0.000 \\
\hline Condoms/others & 2.85 & 0.30 & 0.000 \\
\hline
\end{tabular}

Walḍ $\mathrm{X}^{2}$

521.66

Probability

0.00

(N)

The Impact of Quality of Care

on Contraceptive Use 
Table 3. The effects of programmatic and non-programmatic variables on all method contraceptive continuation, rural Bangladesh, 1989-93

\begin{tabular}{|c|c|c|c|}
\hline Variable & Hazard ratio & S.E. & $p$ value \\
\hline \multicolumn{4}{|l|}{ Programmatic variables } \\
\hline \multicolumn{4}{|l|}{ Fieldworker quality of care } \\
\hline Low (RC) & 1.00 & & \\
\hline Moderate & 0.82 & 0.09 & 0.078 \\
\hline High & 0.72 & 0.11 & 0.032 \\
\hline Very high & 0.66 & 0.10 & 0.006 \\
\hline Fieldworker visitation $<6$ months & 0.68 & 0.14 & 0.065 \\
\hline \multicolumn{4}{|l|}{ Clinic quality of care } \\
\hline Low (RC) & 1.00 & & \\
\hline Moderate & 0.88 & 0.12 & 0.342 \\
\hline High & 1.15 & 0.14 & 0.248 \\
\hline Distance to clinic & 1.02 & 0.04 & 0.539 \\
\hline \multicolumn{4}{|l|}{ Non-programmatic } \\
\hline \multicolumn{4}{|l|}{ Women's age } \\
\hline$<25$ years $(\mathrm{RC})$ & 1.00 & & \\
\hline $25-34$ years & 0.66 & 0.04 & 0.000 \\
\hline $35+$ years & 0.57 & 0.05 & 0.000 \\
\hline \multicolumn{4}{|l|}{ Women's education } \\
\hline None $(\mathrm{RC})$ & 1.00 & & \\
\hline $1-5$ years & 0.86 & 0.06 & 0.023 \\
\hline $6+$ years & 0.69 & 0.08 & 0.001 \\
\hline \multicolumn{4}{|l|}{ Desire for additional children } \\
\hline $1+$ more $(\mathrm{RC})$ & 1.00 & & \\
\hline No more & 0.71 & 0.04 & 0.000 \\
\hline Up to God & 1.13 & 0.08 & 0.097 \\
\hline \multicolumn{4}{|l|}{ Religion } \\
\hline Muslim (RC) & 1.00 & & \\
\hline Non-Muslim & 0.90 & 0.08 & 0.258 \\
\hline Household area (log) & 0.98 & 0.05 & 0.706 \\
\hline \multicolumn{4}{|l|}{ Electricity } \\
\hline No $(\mathrm{RC})$ & 1.00 & & \\
\hline Yes & 0.97 & 0.09 & 0.744 \\
\hline Women's status & 1.14 & 0.08 & 0.069 \\
\hline \multicolumn{4}{|l|}{ Contraceptive Method } \\
\hline Oral pills & 2.31 & 0.26 & 0.000 \\
\hline Injectables & 2.39 & 0.37 & 0.000 \\
\hline Condoms/others & 2.44 & 0.32 & 0.000 \\
\hline Wald $\mathrm{X}^{2}$ & 387.90 & & \\
\hline $\begin{array}{l}\text { Probability } \\
\text { (N) }\end{array}$ & $\begin{array}{l}\text { The Impact of Quality of Care } \\
\text { on Contraceptive Use } \\
12\end{array}$ & & \\
\hline
\end{tabular}


Figure 1. Effects of Fieldworker and Clinic Quality of Care on Contraceptive Adoption, Rural Bangladesh, 1989-93

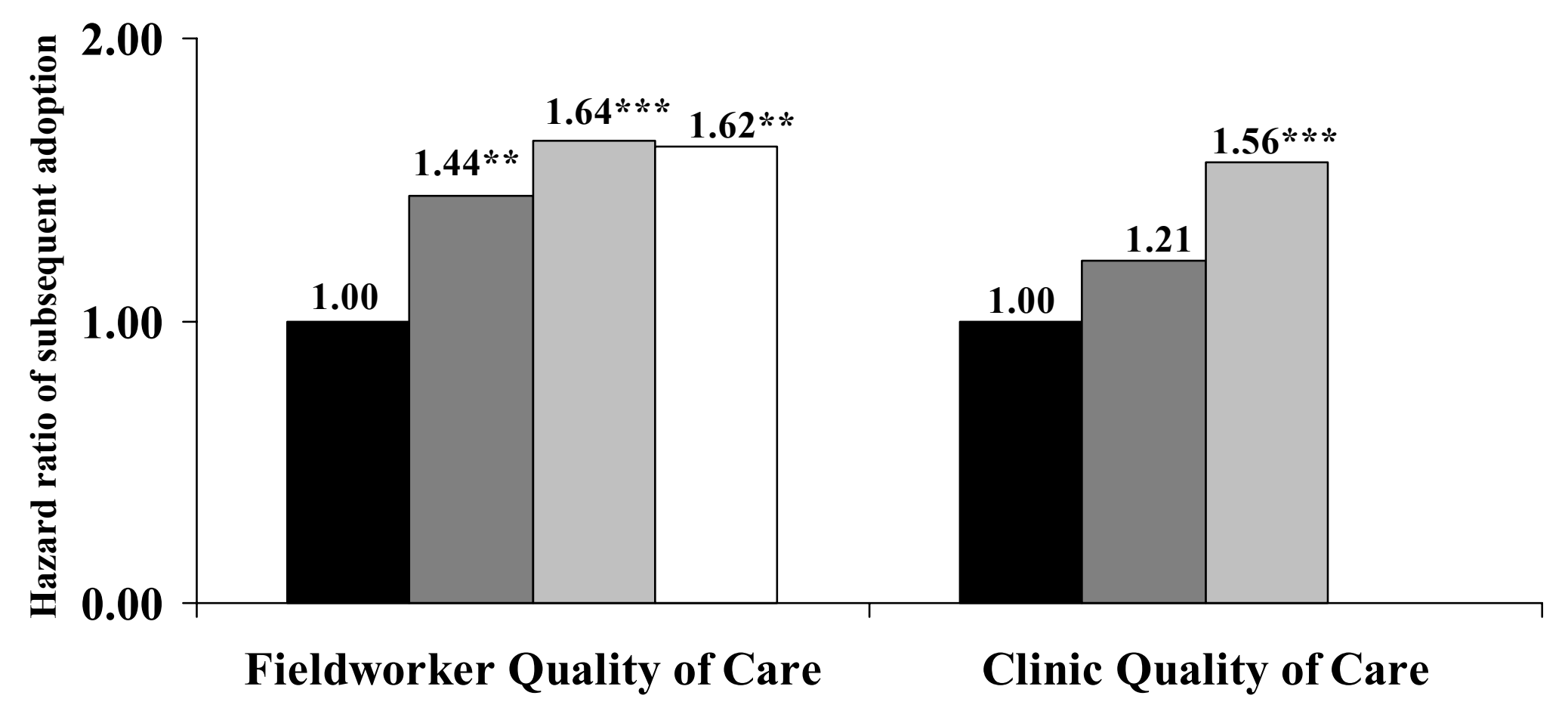

$\square$ Low $\square$ Medium $\square$ High $\square$ Very High 
Figure 2. Effects of Fieldworker and Clinic Quality of Care on All-method Contraceptive Discontinuation, Rural Bangladesh, 1989-93

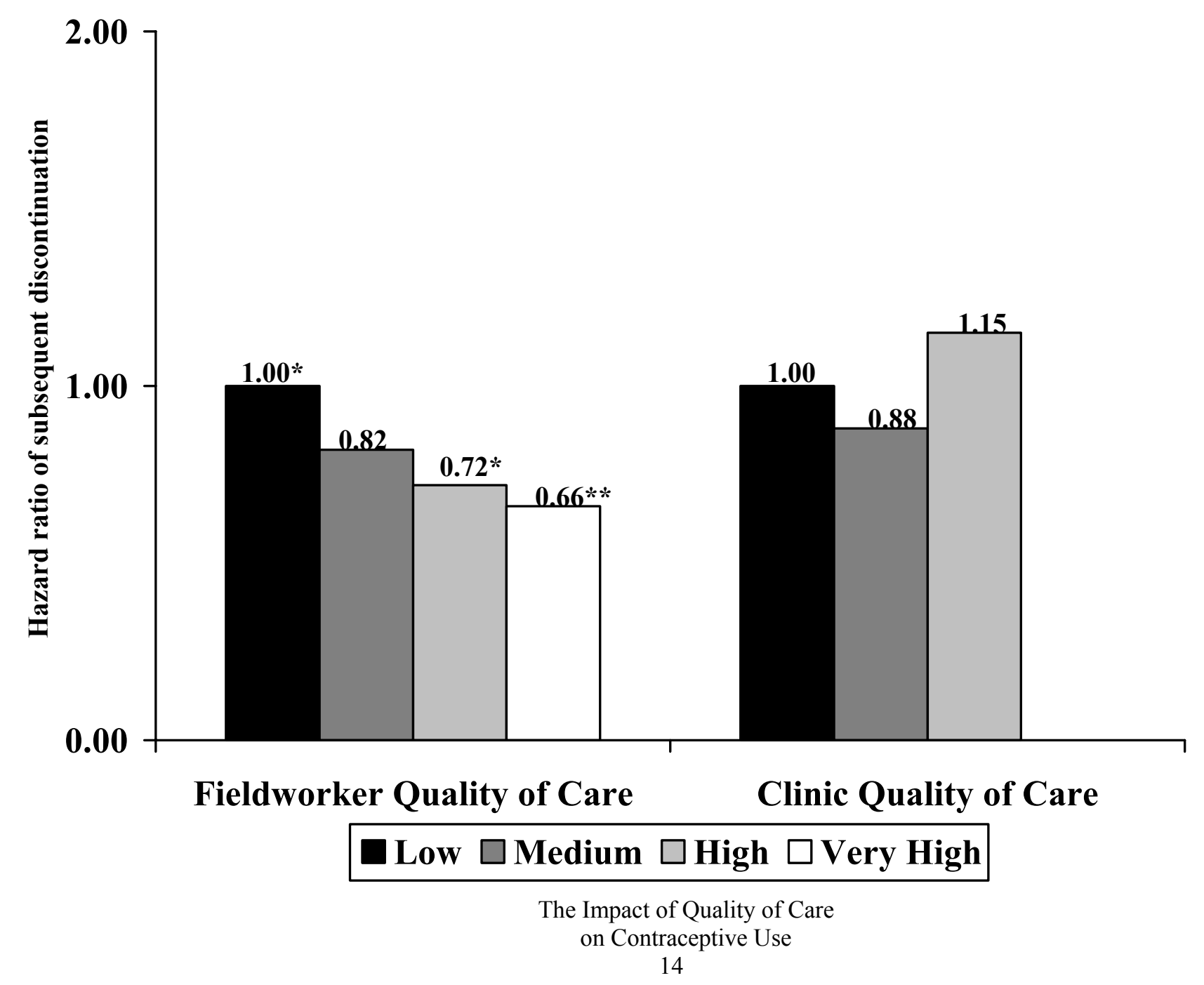


Figure 3. Effect of Fieldworker Quality of Care on Contraceptive Adoption and Discontinuation by Socioeconomic Status, Rural Bangladesh, 1989-93

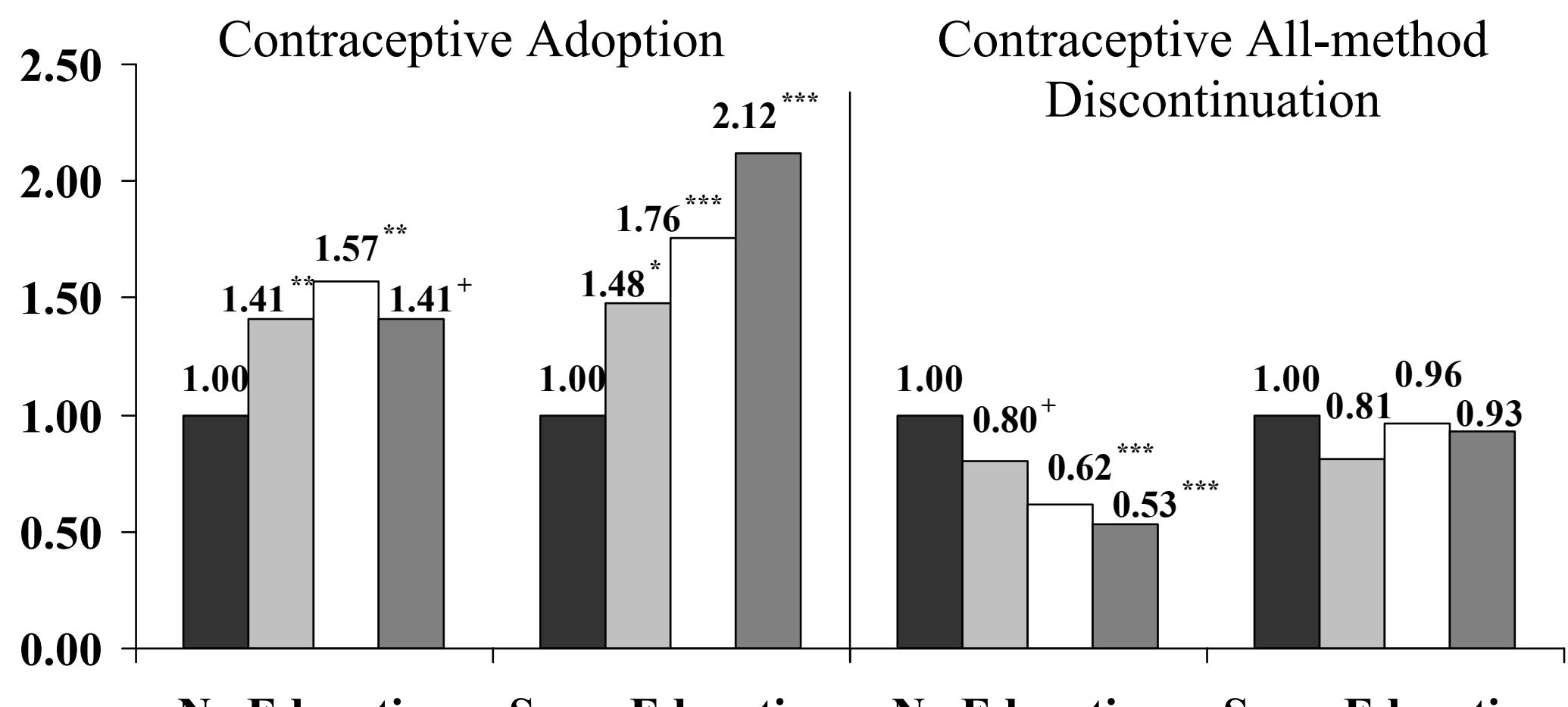

No Education Some Education No Education Some Education

$\square$ Low $\square$ Moderate $\square$ High $\square$ Very High

$$
{ }^{+} \mathrm{p}<.10,{ }^{*} \mathrm{p}<.05,{ }^{* *} \mathrm{p}<.01,{ }^{* * *} \mathrm{p}<.001
$$




\section{References}

Angeles, G., D. Guilkey, and T.A. Mroz. "Purposive program placement and the estimation of family planning program effects in Tanzania." Journal of the American Statististical Association 93, 443 (1998): 884-899.

Bertrand, J.T., R.J. Magnani, and N. Rutenberg. Evaluating Family Planning Programs: With Adaptions for Reproductive Health. Chapel Hill: The EVALUATION Project, 1996.

Bollen, K.A., D. Guilkey, and T.A. Mroz. "Binary outcomes and endogenous explanatory variables: tests and solutions with an application to the demand for contraceptive use in Tunisia." Demography 32, 1 (1995): 111-131.

Bruce, J. "Fundamental elements of the quality of care: A simple framework." Studies in Family Planning 21, 2 (1990): 61-91.

Cotten, N., J. Stanback, H. Maidouka, J.T. Taylor-Thomas, and T. Turk. "Early discontinuation of contraceptive use in Niger and The Gambia." International Family Planning Perspectives 18, 4 (1992): 145-149.

Koenig, M.A., M.B. Hossain, and M. Whittaker. "The influence of quality of care upon contraceptive use in rural Bangladesh.” Studies in Family Planning 28, 4 (1997): 278-289.

Lei, Z.-W., S.C.Wu, R.J. Garceau, et al. "Effect of pretreatment counseling on discontinuation rates in Chinese women given depo-medroxyprogesterone acetate for contraception." Contraception 53 (1996): 357-361.

Magnani, R., Hotchkiss et al. "Impact of the Family Planning Supply Environment on Contraceptive Intentions and Use in Morocco Studies in Family Planning 30, 2 (1999): 120-132.

Mensch, B., M. Arends-Kuenning, and A. Jain. "The impact of the quality of family planning services on contraceptive use in Peru." Studies in Family Planning 27, 2 (1996): 59-75.

Mensch, B., M. Arends-Kuenning, A. Jain, and M. R. Garate. "Avoiding unintended pregnancy in Peru: Does the quality of family planning services matter?" International Family Planning Perspectives 23, 1 (1997): 21-27.

Mroz, T., K.A. Bollen, I. S. Speizer, and D. J. Mancini. "Quality, accessibility, and contraceptive use in rural Tanzania.” Demography 36, 1 (1999): 23-40.

Pariani, S., D.M. Heer, and M.D. Van Arsdol, Jr. "Does choice make a difference to contraceptive use? Evidence from East Java.” Studies in Family Planning 22, 6 (1991): 384-390.

Patel, D., A. Patel, and A. Mehta. "The effects of service quality on IUD continuation among women in rural Gujarat," in M.A. Koenig and M.E. Khan (eds.) Quality of Care within the Indian Family Planning Program. New York, The Population Council, 1999.

Sanogo, D. et al. "Improving Quality and Contraceptive Use in Senegal.” Unpublished paper, 2003. 
Steele, F., S.L. Curtis, and M. Choe. "The impact of family planning service provision on contraceptiveuse dynamics in Morocco." Studies in Family Planning 30,1 (1999): 28-42.

Vera, H. "The Client's View of High Quality Care in Santiago, Chile." Studies in Family Planning 24,1 (1993): 40-49. 